\title{
NMR-based localization of ions involved in salting out of hen egg white lysozyme
}

\author{
Jarosław Poznański ${ }^{凶}$ \\ Institute of Biochemistry and Biophysics, Polish Academy of Sciences, Warszawa, Poland; Institute of Physical

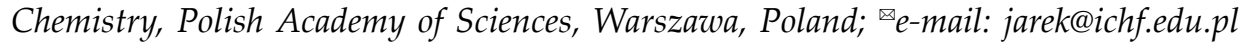

Received: 28 March, 2006; revised: 11 April, 2006; accepted: 30 May, 2006

available on-line: 13 June, 2006

\begin{abstract}
NaCl-induced aggregation of hen egg white lysozyme (HEWL) was monitored by NMR spectroscopy. Small, but significant, changes induced by salt addition in TOCSY spectra were attributed to the effect of local reorganization of protein backbone upon ion binding. Salt-induced variations in $\mathrm{HN}$ and $\mathrm{H} \alpha$ chemical shifts were mapped on the HEWL 3D structure which allowed the construction of a scheme of the spatial localization of potential ion binding sites. It was found that in a $0.5 \mathrm{M} \mathrm{NaCl}$ solution six chloride anions and at least one sodium cation are bound to preferred sites on the HEWL surface.
\end{abstract}

Keywords: NMR, HEWL, lysozyme, salting out, ion binding

\section{INTRODUCTION}

Hen egg white lysozyme aggregation offers a model for investigation of the process of protein crystallization. Theoretical studies on the kinetics of crystal nucleation predicted formation of fractal-like aggregates as morphologically unstable intermediates during the crystal growth (Xiao et al., 1988; Alexander, 1995). Since that time HEWL aggregation has been intensively studied by numerous experimental techniques, including light scattering (Tanaka et al., 1996; Georgalis et al., 1997; Georgalis \& Saenger, 1999; Poznański et al., 2005a), neutron scattering (Niimura et al., 1994), X-ray diffraction (Narayanan \& Liu, 2003), NMR (Price et al., 2001; Poznański et al., 2005a) and calorimetry (Schall et al., 1996; Georgalis et al., 1997; Poznański et al., 2004; 2005b). Results of all these studies pointed out that the observed concentration dependence of the saltinduced protein aggregation is due to the screening of electrostatic interactions by nonspecific binding of electrolyte counter ions to the charged solvent-exposed functional groups, which in turn reduces intermolecular repulsion forces (Ries-Kautt \& Ducruix, 1989; Georgalis et al., 1999; Retailleau et al., 2002). Fluorescence quenching studies proved that in di- luted solution HEWL binds weakly 21-23 chloride anions per molecule (Sibille \& Pusey, 1994), which is consistent with the results of calorimetric titration experiments (Poznański et al., 2004). High-resolution crystal structures of HEWL determined for its triclinic (Walsh et al., 1998), monoclinic (Steinrauf, 1998), orthorhombic (Oki et al., 1999) and tetragonal (Lim et al., 1998; Vaney et al., 2001; Sauter et al., 2001) forms demonstrated the presence of up to eight well resolved chloride anions in the crystal cell (Dauter \& Dauter, 1999). Iodide anions were also found to substitute in HEWL crystals some of water molecules in the ordered solvation shell, occupying partially over a dozen of weekly binding sites (Dauter et al., 2000).

Calorimetric measurements confirmed the occurrence of an aggregation process preceding protein crystallization (Georgalis et al., 1997; Poznański et al., 2004) and demonstrated that the specific salting out effect becomes the largest in about $0.6 \mathrm{M} \mathrm{NaCl}$ solution (Poznański et al., 2005b). The early steps of salt-induced HEWL aggregation followed by timeresolved dynamic light scattering (DLS) have shown a systematic increase of the aggregates' size during the first hours after protein dissolution (Poznański et al., 2005a). A systematic decrease of translational and rotational diffusion rates, monitored by NMR 
methods, indicated that the efficient buildup of still larger systems is initiated about $76 \mathrm{~h}$ after the addition of $0.5 \mathrm{M} \mathrm{NaCl}$ (Poznański et al., 2005a). To get a deeper insight into the mechanism of the protein salting out phenomena, in this work salt-induced variations in ${ }^{1} \mathrm{H}$ NMR spectra of HEWL were monitored and analysed in terms of changes induced in the protein structure.

\section{MATERIALS AND METHODS}

Hen egg white lysozyme was purchased from Fluka (Lot no. 62970) and further purified by dialysis against water (deionization) and then lyophilized. The final purity of HEWL was checked by mass spectrometry, as described previously (Poznański et al., 2003). $\mathrm{NaCl}$ used in the experiment was of the analytical grade. All experiments were performed in $0.1 \mathrm{M}$ sodium acetate buffer at $\mathrm{pH} 4.25$. Stock salt solutions were prepared by weight. Protein concentration was determined spectrophotometrically at $280 \mathrm{~nm}$ (Shimadzu UV/VIS 2401-PC) assuming an absorption coefficient of 26.4 for $1 \%$ (w/v) HEWL solution in a $1 \mathrm{~cm}$ cell (Anue \& Tanfort, 1969). All the solutions were prepared using distilled and deionized water.

NMR experiments were carried on a Varian Unity Plus $500 \mathrm{MHz}$ NMR spectrometer at $298 \mathrm{~K}$ using 2.1 mM HEWL solution in the pure buffer and in the presence of 0.3 or $0.5 \mathrm{M} \mathrm{NaCl} .{ }^{1} \mathrm{H}-{ }^{1} \mathrm{H}$ 2D-TOCSY and 2D-DOSY spectra were cyclically recorded from about 45 min up to about $96 \mathrm{~h}$ after mixing of lysozyme and $\mathrm{NaCl}$ solutions (including $30 \mathrm{~min}$ of acquisition time).

NMR spectra were processed with the aid of NMRPipe software (Delaglio et al., 1995) using standard methods of $\pi / 2$ square sine-bell filtering and zero-filling preceding Fourier transform in both direct and indirect frequency dimensions. The spectra were analyzed using Sparky program (Goddard \& Kneller, 2003). Resonance assignment was adopted from BioMagResBank BMRB4562 record (Wang et al., 2000).

Structure-related analyses were carried out with the aid of MolMol program (Koradi et al., 1996) and HEWL structure was taken from Protein Data Bank 1lks record (Steinrauf, 1998).

\section{RESULTS AND DISCUSSION}

Kinetics of HEWL aggregation was followed by NMR spectroscopy. A comparison of TOCSY spectra for a $2.1 \mathrm{mM}$ protein solution in $0.5 \mathrm{NaCl}$ recorded $45 \mathrm{~min}$ and $96 \mathrm{~h}$ after protein dissolution did not show any significant time-dependent changes in the resonance locations. This indicates a lack of any significant changes in the HEWL backbone conformation upon aggregation and points towards a fractal-like organization of the aggregates. In such case, the relatively sparse intermolecular contacts in the fractal network apparently do not influence the averaged chemical neighborhood of the protein backbone, and, in consequence, the proton chemical shifts remain unchanged. Representative fragments of superimposed TOCSY spectra are presented in Fig. 1. A detailed analysis of the resonance line-shapes proved that despite the lack of aggregation-induced changes in the positions of the resonance lines they are broadened due to an increased efficiency of nuclear relaxation in the aggregated protein. Generally, the larger a protein is (or the slower its tumbling in solution), the wider are the resonance lines.

A comparison of the TOCSY spectra of HEWL recorded at different $\mathrm{NaCl}$ concentrations (Fig. 1, bottom) demonstrated the occurrence of changes in the position of numerous resonance lines. However, positions of some of the lines remained unchanged. These observations can be explained in the following way. The bound ions may affect the proximal amino-acid residues according to two alternative mechanisms. The first one involves their direct electrostatic interaction with atomic electron shells, which influences the magnetic screening of nuclei causing changes in proton chemical shifts resulting in a movement of signals in the TOCSY spectrum. According to the second mechanism, ion binding may induce small conformational changes in the protein structure affecting the nuclear resonance frequencies. For heavy atoms, ${ }^{13} \mathrm{C}$ or ${ }^{15} \mathrm{~N}$, the second mechanism is expected to dominate.

In the three TOCSY spectra presented in Fig. 1 signals from Val2, Asn39, Thr43, Asp52, Cys64, and Asp119 overlap precisely, indicating that no changes in the protein structure are induced by salt addition. Some weak signals (Thr51, Asn59, Arg68, and Asp101) disappear, which can be attributed to the effect of signal broadening caused either by changes in the mobility of the amino-acid residues or by their direct interaction with weekly bound salt ions. A third group of signals, represented by Asn46, Asp66, Leu84, experience some changes upon addition of $0.3 \mathrm{M} \mathrm{NaCl}$, but a further increase in salt concentration does not affect their position. The last group, represented by Ser60, Asn65, Ile78 and Cys94, exhibits systematic changes of resonance position with an increase in salt concentration.

The individual patterns of resonance response to salt addition allow the identification of the protein regions involved in ion binding. The average changes in resonance position, defined as the geometrical shift in the TOCSY spectrum, could be thus assigned to particular residues in the protein sequence, and, 

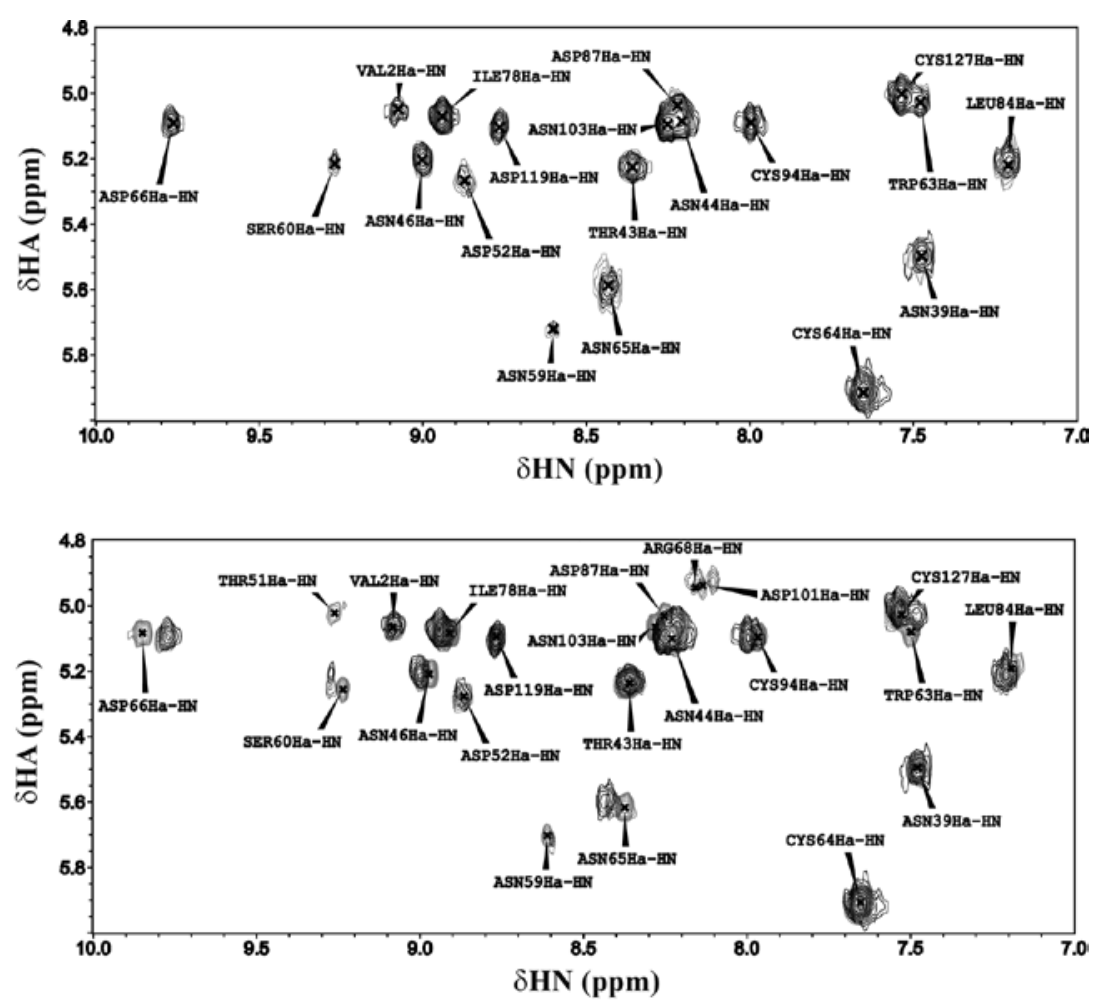

Figure 1. Effect of $\mathrm{NaCl}$ on ${ }^{1} \mathrm{H}$ TOCSY spectra of HEWL.

Comparison of the spectra recorded in $0.5 \mathrm{M} \mathrm{NaCl}$ aqueous solution 45 min (black) and 96 h (grey) after salt addition (top), and spectra of aqueous (grey), $0.3 \mathrm{M} \mathrm{NaCl}$ (dotted) and $0.5 \mathrm{M}$ $\mathrm{NaCl}$ (black) HEWL solution recorded $45 \mathrm{~min}$ after sample preparation (bottom). Resonance assignment is adopted from BioMagResBank BMRB4562 record (Wang et al., 2000). in consequence, mapped on the three-dimensional protein structure. The spatial localization of residues experiencing the largest changes in chemical shift corresponds to the putative ion binding sites. In Fig. 2 changes in chemical shifts induced by addition of $0.5 \mathrm{M} \mathrm{NaCl}$ are mapped on the HEWL structure. The width of the tube following the protein backbone represents the observed salt-induced ${ }^{1} \mathrm{H}$ chemical shift variations.
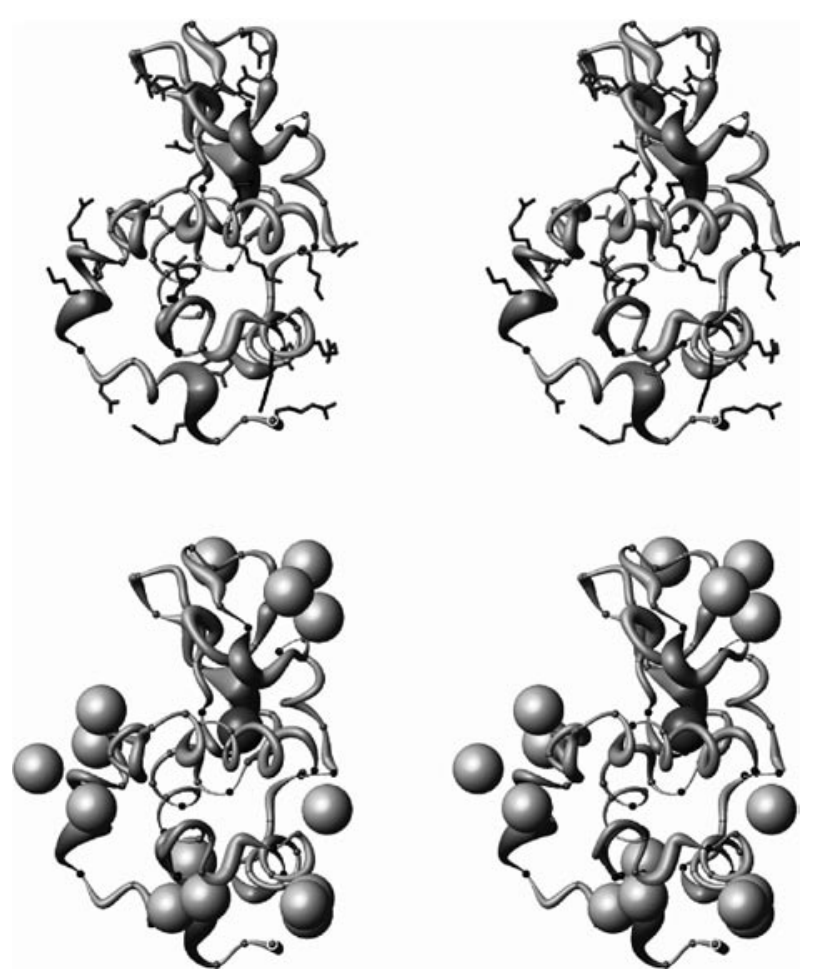

According to the results presented in Fig. 2, there are at least seven regions in the HEWL structure which experience large changes in proton chemical shifts upon salt addition. Localization of six of them remains in agreement with the partial occupancy of iodide anions found in HEWL crystal structure (Steinrauf, 1998; Evans \& Bricogne, 2002); the seventh one, found in the proximity of the protein cleft, is distant from any of the potential anionbinding sites, but its localization is similar to that of a sodium cation in HEWL crystal structure (Evans \& Bricogne, 2002). It can be thus concluded that the NMR measurements allowed proposing the spatial localization of anions weekly bound to amino-acid residues on the HEWL surface. The data proves also that in aqueous solution in the presence of salt at least one cation is also bound to the HEWL surface in the proximity of the cleft region. In view of these findings the process of HEWL crystallization should

Figure 2. ${ }^{1} \mathrm{H}$ NMR chemical shift changes of HEWL $\mathrm{H} \alpha$ and $\mathrm{HN}$ resonances upon addition of $0.5 \mathrm{M} \mathrm{NaCl}$ mapped on the protein structure.

The width of the tube following the protein backbone trace (1lks PDB record, Steinrauf, 1998) is proportional to the determined resonance movement in the TOCSY spectrum. Small grey balls mark the $\mathrm{C} \alpha$ atoms of the residues for which the chemical shifts were determined while black ones mark residues for which the signals were not detected. Side-chains of charged residues are represented as light grey or dark grey balls corresponding to acidic and basic residues, respectively. In the bottom pair, the localization of iodide (light spheres) and sodium (dark sphere) ions is presented, according to the $11 \mathrm{kr}$ (Steinrauf, 1998) and 1gwd (Evans \& Bricogne, 2002) PDB records. 
be reinterpreted to include both anion and cation concentration effects. Moreover, also the purity of all the buffers used routinely in sample preparation should be judged taking into account both anion and cation types introduced to the protein solution.

\section{REFERENCES}

Alexander DJI (1995) Lattice Models. In Science and Technology of Crystal Growth (van der Eerden JP, Bruinsma OSL, eds) pp 81-95, Kluwer Academic Publishers, The Netherlands.

Dauter Z, Dauter M (1999) Anomalous signal of solvent bromides used for phasing of lysozyme. J Mol Biol 289: 93-101.

Dauter Z, Dauter M, Rajashankar KR (2000) Novel approach to phasing proteins: derivatization by short cryo-soaking with halides. Acta Crystallogr D 56: 232237.

Delaglio F, Grzesiek S, Vuister GW, Zhu G, Pfeifer J, Bax A (1995) NMRPipe: a multidimensional spectral processing system based on UNIX pipes. J Biomol NMR 6: $277-293$.

Evans G, Bricogne G (2002) Triiodide derivatization and combinatorial counter-ion replacement: two methods for enhancing phasing signal using laboratory $\mathrm{Cu} \mathrm{K}$ alpha X-ray equipment. Acta Crystallogr D 58: 976-991.

Georgalis Y, Saenger W (1999) Light scattering studies on supersaturated protein solutions. Sci Prog 82: 271-294.

Georgalis Y, Umbach P, Zielenkiewicz A, Utzig E, Zielenkiewicz W, Zielenkiewicz P, Saenger W (1997) Microcalorimetric and small-angle light scattering studies on nucleating lysozyme solutions. J Am Chem Soc 119: 11959-11965.

Goddard TD, Kneller DG (2003) SPARKY 3, University of California, San Francisco.

Koradi R, Billeter M, Wuthrich K (1996) MOLMOL: A program for display and analysis of macromolecular structures J Mol Graphics 14: 51-57.

Lim K, Nadarajah A, Forsythe EL, Pusey ML (1998) Locations of bromide ions in tetragonal lysozyme crystals Acta Crystallogr D 54: 899-904.

Narayanan J, Liu XY (2003) Protein interactions in undersaturated and supersaturated solutions: a study using light and X-ray scattering. Biophys J 84: 523-532.

Niimura N, Minezaki Y, Ataka M, Katsura T (1994) Small angle neutron scattering from lysozyme in unsaturated solutions, to characterize the pre-crystallization process. J Crystal Growth 137: 671-675.

Oki H, Matsuura Y, Komatsu H, Komatsu H, Chernov AA (1999) Refined structure of orthorhombic lysozyme crystallized at high temperature: correlation between morphology and intermolecular contacts Acta Crystallogr D 55: 114-121.

Poznański J, Georgalis Y, Wehr L, Saenger W, Zielenkiewicz P (2003) Comparison of two different lysozyme types under native and crystallization conditions using two-dimensional NMR and dynamic light scattering. Biophys Chem 104: 605-616.

Poznański J, Wszelaka-Rylik M, Zielenkiewicz W (2004) Concentration dependencies of $\mathrm{NaCl}$ salting of lysozyme by calorimetric methods Thermochim Acta 409: 25-32.

Poznański J, Szymański J, Basińska T, Słomkowski S, Zielenkiewicz W (2005a) Aggregation of aqueous lysozyme solutions followed by dynamic light scattering and ${ }^{1} \mathrm{H}$ NMR spectroscopy. J Mol Liq 121: 21-26.

Poznański J, Wszelaka-Rylik M, Zielenkiewicz W (2005b) HEW lysozyme salting by high-concentration $\mathrm{NaCl}$ solutions followed by titration calorimetry. Biophys Chem 113: 137-144.

Price WS, Tsuchiya F, Arata Y (2001) Time dependence of aggregation in crystallizing lysozyme solutions probed using NMR self-diffusion measurements Biophys $J$ 80: 1585-1590.

Retailleau P, Ducruix A, Ries-Kautt M (2002) Importance of the nature of anions in lysozyme crystallisation correlated with protein net charge variation. Acta Crystal$\log r$ D 58: 1576-1581.

Ries-Kautt MM, Ducruix AF (1989) Relative effectiveness of various ions on the solubility and crystal growth of lysozyme. J Biol Chem 264: 745-748.

Sauter C, Otalora F, Gavira JA, Vidal O, Giege R, GarciaRuiz JM (2001) Structure of tetragonal hen egg-white lysozyme at 0.94 angstrom from crystals grown by the counter-diffusion method Acta Crystallogr D 57: 11191126.

Schall CA, Arnold E, Wiencek JM (1996) Enthalpy of crystallization of hen egg-white lysozyme J Crystal Growth 165: 293-298.

Sibille L, Pusey ML (1994) Investigation of nucleating lysozyme solutions. Acta Crystallogr D 50: 396-397.

Steinrauf LK (1998) Structures of monoclinic lysozyme iodide at 1.6 angstrom and of triclinic lysozyme nitrate at 1.1 angstrom. Acta Crystallogr D 54: 767-779.

Tanaka S, Yamamoto M, Kawashima K, Ito K, Hayakawa R, Ataka M (1996) Kinetic study on the early stage of the crystallization process of two forms of lysozyme crystals by photon correlation spectroscopy. J Crystal Growth 168: 44-49.

Vaney MC, Broutin I, Retailleau P, Douangamath A, Lafont S, Hamiaux C, Prange T, Ducruix A, Ries-Kautt M (2001) Structural effects of monovalent anions on polymorphic lysozyme crystals. Acta Crystallogr D 57: 929-940.

Walsh MA, Schneider TR, Sieker LC, Dauter Z, Lamzin VS, Wilson KS (1998) Refinement of triclinic hen eggwhite lysozyme at atomic resolution. Acta Crystallogr D 54: 522-546.

Wang YJ, Bjorndahl TC, Wishart DS (2000) Complete H1 and non-carbonylic C-13 assignments of native hen egg-white lysozyme. J Biomol NMR 17: 83-84.

Xiao RF, Alexander JID, Rosenberger F (1988) Morphological evolution of growing crystals: A Monte Carlo simulation. Phys Rev A 38: 2447-2456. 